\title{
ENTREVISTA COM O PROFESSOR DOUTOR JAIME MORELES VÁZQUEZ - UNIVERSIDADE DE COLIMA - MÉXICO
}

\section{POLÍTICAS DE AVALIAÇÃO DE INVESTIGADORES NO MÉXICO}

Marilda Pasqual Schneider*

Resumo: Doutor Jaime Moreles Vázquez é Professor da Faculdade de Pedagogia da Universidade de Colima, México. Pertence ao Sistema Nacional Investigadores, nível 1, do Conselho Nacional de Ciência e Tecnología (Conacyt). Seus estudos oferecem importantes recursos teóricos e conceituais para compreender o uso da investigação, as políticas educativas e as práticas científicas. Sobre esses tópicos, publicou artigos em revistas especializadas, livros e capítulos de livros, destacando-se, entre eles: Productivismo: ¿Publish or Perish o Publish and Prosper?, la distorsión de las prácticas académicas y científicas; Sinéctica, publicado em 2015 pela Sinectica; El campo teórico de la política educativa y su objeto de estudio. Reflexiones a partir de la revisión de algunos estudios publicados en México, capítulo de livro, no prelo, pela Mercado de Letras.

A entrevista que segue foi motivada pela participação do Professor Jaime no Programa de Pós-graduação em Educação da Universidade do Oeste de Santa Catarina, como Professor visitante do PPGEd, no período de 21 a 29 de março de 2015 e por sua participação no Seminário Internacional de Políticas e Processos Educativos: Avaliação e regulação da educação em contextos ibero e latino-americanos, promovido pelo PPGEd entre 30 e 31 de março de 2015, no qual proferiu palestra na sessão temática Políticas para qualidade e práticas educativas na educação superior.

Palavras-chave: Políticas de avaliação. Investigadores em educação. Produtividade docente.

\footnotetext{
* ós-doutora em Políticas educacionais pela Universidade do Minho, Portugal; Doutora em Educação pela Universidade Federal de Santa Catarina; Professora titular do Programa de Pós-graduação em Educação da Universidade do Oeste de Santa Catarina; marilda.schneider@unoesc.edu.br
} 
Marilda (M): Os seus temas de investigação perpassam as políticas de avaliação dos investigadores. Poderia discorrer que políticas são essas e como elas funcionam no México?

Jaime Moreles Vázquez (JMV): Las políticas de evaluación de académicos son instrumentadas en dos programas, el Programa para el Desarrollo Docente (PRODEP) y el Sistema Nacional de Investigadores (SNI). El primero es coordinado por la Dirección de Superación Académica (DSA) de la Subsecretaría de Educación Superior, y el segundo por el Consejo Nacional de Ciencia y Tecnología (Conacyt). Son programas que evalúan las funciones académicas de los profesores-investigadores de Tiempo Completo que laboran en las instituciones de educación superior mexicanas; en el caso del SNI se consideran algunos pesquisadores adscritos a instituciones fuera de México. Las funciones son docencia, pesquisa, tutoría, gestión y difusión. Entre esos programas, una de las diferencias más importantes consiste en la evaluación y valoración de la pesquisa; por ejemplo, el Programa del SNI promueve un tanto más la pesquisa y producción individual, mientras que el Programa del PRODEP fomenta la producción colegiada. También difieren en la valoración de los productos evaluados, pues en el SNI se privilegian publicaciones en medios con arbitraje más riguroso. En el plano institucional existen en la mayoría de las instituciones de educación superior mexicanas programas de Estimulos al Desempeño Docente, que de alguna manera reproducen las evaluaciones de los dos programas mencionados. Una de las principales diferencias es que en este caso la evaluación es anual, mientras que para el PRODEP puede ser cada tres o seis años, y para el SNI cada tres, cuatro o incluso más años según el tipo de nombremiento que el pesquisador posea.

M: Que estímulos essas políticas oferecem aos investigadores e quais repercussões têm sido verificadas na atuação dos pesquisadores e no modo como lidam com a pesquisa em educação?

JMV: Las dos que mencionaba ofrecen certificados o acreditaciones, el PRODEP otorga un perfil que permite a los académicos que trabajan en las instituciones de educación superior participar en los programas de estímulos que también señalé. El Programa del SNI otorga un reconocimiento que se acompaña de un estímulo económico, y que varía según el tipo de nombramiento (Candidato, Niveles 1, 2 y 3, y Emérito). De manera conjunta, estos incentivos pueden representar hasta más del $30 \%$ de los ingresos mensuales de los pesquisadores mexicanos. Las dos membrecías se asocian a programas de financiamiento para las instituciones de pertenencia de los pesquisadores; por ello los programas tienen repercusiones financieras tanto para los 
investigadores como para las universidades a las que éstos pertenecen. Asimismo, la pertenencia al SNI y al PRODEP otorgan cierta reputación a los pesquisadores, aunque existe cierto consenso respecto a la preminencia del primero, en tanto a que certifica la realización de pesquisa original.

M: Seus estudos têm evidenciado repercussões dessas políticas também na atuação dos investigadores como docentes? Poderia citar algumas delas e que consequências são observadas na formação de futuros pesquisadores da área da Educação?

JMV: Considero que las implicaciones de esos programas de evaluación en el trabajo de los pesquisadores son importantes, puesto que al asociarse a incentivos económicos, han generado resultados o efectos no deseados. Como ha ocurrido con otras políticas, esos programas han trastocado las actividades académicas, incluso desvirtuando sus propósitos. La bibliografia correspondiente habla de una suerte de seudo-academia en la que nos hemos implicado, realizando solamente actividades que estén consideradas en los indicadores que toman en cuenta los programas de evaluación. Algunos de esos efectos son los relativos a las malas conductas (research misconduct) y las prácticas cuestionables de la investigación (questionable research practice). Las primeras son un tanto más mediáticas y se refieren al plagio, la falsificación y fabricación de evidencias; las segundas son aún más graves puesto que se han normalizado en la rutina cotidiana, y van desde la explotación de estudiantes y asistentes de investigación, hasta el robo de ideas cuando participamos en la evaluación de proyectos de pesquisa o en la dictaminación de papers. Además, el trastocamiento de las actividades académicas, la búsqueda de indicadores, productos o resultados, inhibe la innovación y hasta la repercusión de la investigación en las prácticas educacionales en donde se le pudiera tener en cuenta. Cada vez parece más claro que nuestras actividades se significan solamente en el resultado, sin importar el proceso seguido para lograrlo. Todas estas cuestiones representan riesgos para la formación de futuros pesquisadores, puesto que en los procesos de aculturación de las disciplinas se transmiten y reproducen este tipo de valores, tradiciones y prácticas. Lo realmente inquietante es que algunas de estas prácticas se han normalizado en las actividades académicas cotidianas, haciéndose parte del legado que inculcamos a los aprendices o novatos del oficio científico.

M: Percebe alguma similaridade entre as políticas de avaliação dos investigadores no México e em outros países? Em que aspectos considera que elas são díspares e em que aspectos as considera similares? 
JMV: Las experiencias sólo las conozco desde la bibliografia correspondiente, desde la evidencia anecdótica de mis conversaciones con colegas de otros países y de una de mis recientes pesquisas. Como ocurre en México, en otros países los programas de evaluación sí se asocian a incentivos, aunque el peso que tienen en el salario total no son tan importantes como sucede en mi país. Otro de los aspectos en común son los resultados no deseados de los programas de evaluación, y que se refieren a la exacerbación de las malas conductas y conductas cuestionables que ya he señalado. También hay cierto paralelismo en la cuestión de la escasa pertinencia que la pesquisa en educación tiene para las prácticas y las políticas correspondientes, pues el incremento de conocimiento (y de papers) parece no estar relacionado con el abatimiento de los problemas educativos y sociales.

M: A exemplo do que ocorreu nos Estados Unidos e em outros países, experiências internacionais vêm indicando a necessidade de implantação de políticas de responsabilização dos professores pelos resultados educacionais dos estudantes. Como o senhor analisa essa perspectiva, considerando as consequências das políticas de avaliação e regulação do trabalho dos investigadores no México?

JMV: Pienso que es un asunto complejo, en el entendido de que los resultados de los estudiantes no dependen únicamente de nuestro trabajo como docentes y pesquisadores. En mi país algo parecido sucede con los profesores de educación básica, pues una parte de sus incentivos económicos depende de los resultados de sus estudiantes en cierto tipo de pruebas. A mi modo de ver, este tipo de mecanismos tienden a perturbar los procesos educativos. Es muy probable que en algún momento algo parecido ocurra con los profesores de educación superior y con el trabajo de los pesquisadores.

M: Considerando, de um lado, o produtivismo acadêmico gerado pelos efeitos da política de avaliação dos programas de pós-graduação e dos investigadores e, de outro, a falta de pesquisas mais aprofundadas, que permitam encontrar alternativas para resolver os problemas atuais da educação enfrentados por muitos países em desenvolvimento, como é o caso do Brasil, quais são, na sua opinião, os principais desafios a serem enfrentados nos próximos 10 anos, na prática da investigação científica?

JMV: Creo que el principal desafio que tiene y tendrá la pesquisa en el campo de la educación es relacionarse con las prácticas y políticas correspondientes. Tener sentido para las actividades de los profesionales de la educación, docentes, di- 
rectivos, padres de família y otros actores sociales. El desafio implica que la pesquisa se salga de las universidades y llegue a los contextos de las prácticas, que es desde donde surgen una buena parte de los problemas que se abordan en las pesquisas. Aquí estoy hablando de manera particular de la investigación en el campo de la educación. Aunque mucho de esto tiene que ver con cuestiones relativas a la organización de la pesquisa en las instituciones, a título personal podemos ir avanzando en la diseminación y divulgación del trabajo que hacemos en los contextos en donde se le puede tener en cuenta. Convertirnos en una suerte de paladines de la investigación. Los desafíos para la investigación científica en general van en un sentido similar. Siempre ha existido la idea de que ésta contribuye al desarrollo social; sin embargo, vale la pena volver a cuestionarnos esta relación, pues aun con los avances actuales en materia de ciencia y tecnología, las brechas de desigualdad persisten y son incluso más graves.

Colima, México, abril de 2015. 
